\title{
Tetraploid Cells of Enhanced Green Fluorescent Protein Transgenic Mice in Tetraploid/Diploid-Chimeric Embryos
}

\author{
Naomi ISHIGURO')\#, Kiyoshi KANO ${ }^{2)}$, Yoshio YAMAMOTO ${ }^{1)}$ and \\ Kazuyuki TANIGUCHI ${ }^{1)}$
}

1)Laboratory of Veterinary Anatomy, Iwate University, 3-18-8 Ueda, Morioka, Iwate 020-8550,

${ }^{2}$ Laboratory of Applied Genetics, Graduate School of Agricultural and Life Sciences, The

University of Tokyo, 1-1-1 Yayoi, Bunkyo-ku, Tokyo 113-8657, Japan

\#Present: Laboratory of Veterinary Physiology, Graduate School of Agricultural and Life

Sciences, The University of Tokyo, 1-1-1 Yayoi, Bunkyo-ku, Tokyo 113-8657, Japan

\begin{abstract}
We succeeded in noninvasively analyzing the distribution of tetraploid (4n) cells in tetraploid $\leftrightarrow$ diploid $(4 n \leftrightarrow 2 n)$ chimeric embryos by using enhanced green fluorescent protein (EGFP) transgenic ( $\mathrm{Tg}$ ) mouse embryos. We also evaluated whether this technique of analyzing $4 \mathrm{n}$-cells in EGFP Tg $4 n \leftrightarrow 2 n$ chimeric embryos could be used to determine which characteristics of $4 n$-cells cause the death of 4 -embryos and restricted distribution of 4 -cells in $4 n \leftrightarrow 2 n$-chimeric embryos after implantation. In our experiments, the distribution of $4 n$-cells in $4 n \leftrightarrow 2 n$-embryos was normal until an embryonic age of 3.5 days (E3.5). With respect to morphological development, there were no differences between $4 n-$, diploid ( $2 n), 4 n \leftrightarrow 2 n-$, and diploid/diploid ( $2 n \leftrightarrow 2 n)$ chimeric embryos, but the number of cells in the tetraploid $(4 n)$ blastocyst was smaller than expected. This decrease in the number of cells may have caused cell death or reduced the rate of cell division in $4 \mathrm{n}$-cells, and may have restricted the distribution of $4 n$-cells in $4 n \leftrightarrow 2 n$-chimeric embryos. This study demonstrated the utility of EGFP transgenic mouse embryos for relatively easy and noninvasive study of the sequential distribution of cells in chimeric embryos.
\end{abstract}

Key words: $4 \mathrm{n} \leftrightarrow 2 \mathrm{n}$-chimeric embryo, EGFP transgenic mouse, Implantation

(J. Reprod. Dev. 51: 567-572, 2005)

E hanced green fluorescent protein (EGFP) is a nontoxic marker that emits green fluorescence without exogenous substrates or cofactors, and it has been proven useful in numerous applications, such as in the selection of transgenic embryos [1]. Because the expression of EGFP can be easily observed by fluorescent microscopy, the use of EGFP transgenic ( $\mathrm{Tg}$ ) mouse embryos may be useful for analyzing the distribution of cells in chimeric embryos.

Accepted for publication: May 9, 2005

Published online: July 21, 2005

Correspondence: K. Kano

(e-mail: akano@mail.ecc.u-tokyo.ac.jp)
Tetraploid (4n) mouse embryos with 80 chromosomes have been produced by either inhibition of cleavage or blastomere fusion [2-5]. These embryos develop into blastocysts in vitro, but with the exception of a report by Snow [6], they are generally not considered to be capable of completing their full-term development $[4,7]$. On the other hand, in vivo tetraploid $\leftrightarrow$ diploid $(4 n \leftrightarrow 2 n)$-chimeric embryos are capable of continuing to develop after implantation, and tetraploid $(4 \mathrm{n})$ cells in those embryos tend to distribute in derivatives of the trophectoderm and primitive endoderm lineages, but not in those of the primitive ectoderm [8]. Because of this 
characteristic of $4 n$-cells, tetraploid (4n) blastocysts are utilized as host embryos to produce embryonic stem cells that contribute effectively to the fetus [911]. Moreover, it has been reported that $4 n \leftrightarrow 2 n-$ chimeric embryos display a restricted distribution of $4 \mathrm{n}$-cells among the mural trophectoderm even at an embryonic age of 3.5 days (E3.5) [12,13], and the contribution of $4 \mathrm{n}$-cells to $4 \mathrm{n} \leftrightarrow 2 \mathrm{n}$-embryos decreases from E3.5 to E4.5 [14].

A noninvasive method for measuring the distribution of cells in chimeric embryos from EGFP Tg mice might provide additional information about living cells without the need for complicated techniques. We therefore examined whether the use of EGFP Tg mice would lead to new insights about the characteristics of $4 n$-cells in the development of $4 n$ - and $4 n \leftrightarrow 2 n$-chimeric embryos.

\section{Materials and Methods}

\section{Collection and culture of embryos}

$\mathrm{C} 3 \mathrm{H} / \mathrm{He}$ female mice were superovulated by i.p. injection of $7.5 \mathrm{IU}$ of equine chorionic gonadtropin (Sankyo, Tokyo, Japan) and, after an interval of 48 h, 7.5 IU of human chorionic gonadotrophin (hCG; Sankyo). After hCG injection, these females were mated with male EGFP Tg C57BL/6 [15] or non-Tg C57BL/ 6 mice. Noon on the day when a vaginal plug was detected was counted as E0.5. Two-cellstage embryos were collected at E1.5 by flushing of the oviducts with $1 \mathrm{mg} / \mathrm{ml}$ of hyaluronidase (Sigma, St. Louis, MO) in M2 medium (Sigma). The embryos were cultured in M16 (Sigma) medium in a humidified atmosphere of $5 \% \mathrm{CO}_{2}$ in air at $37 \mathrm{C}$.

\section{Tetraploidy induction and chimera production}

The production of $4 \mathrm{n}$-embryos was carried out by treatment of 2-cell-stage embryos with cytochalasin B (CB) [Sigma; $1 \mathrm{mg} / \mathrm{ml}$ in dimethyl sulfoxide (DMSO)]. CB was diluted to give a final concentration of $10 \mu \mathrm{g} / \mathrm{ml}$ in M16 medium (CBM16). Two-cell-stage embryos were cultured in CB-M16 medium for $12 \mathrm{~h}$, and washed thoroughly in M16 medium. As a control, 2-cell-stage embryos were cultured in M16 medium containing 1\% DMSO for $12 \mathrm{~h}$. Chimeric embryos were produced by the aggregation method as follows. Eight-cellstage embryos were collected from the oviduct at E2.5, as described for 2-cell-stage embryos. To remove the zona pellucida, the embryos were incubated in pronase (Sigma) solution $(0.5 \%$ in M2 medium) for 5-10 min at $37 \mathrm{C}$. Eight-cell-stage embryos were aggregated with 8-cell-stage EGFP $\mathrm{Tg}$ diploid (2n) embryos of or 4-cell-stage EGFP Tg tetraploid $(4 n)$ embryos. Then, 8-cell-stage non-Tg 2 n-embryos were gently pressed onto 8-cell-stage EGFP Tg 2n-embryos or 4-cell-stage EGFP Tg 4nembryos with a glass capillary.

\section{Cytogenetic and cell number analysis}

The number of chromosomes and the number of cells in embryos were counted [15]. To increase metaphase chromosomes, embryos were precultured in $2 \%$ KaryoMAX colcemid (Gibco/ Invitrogen, Carlsbad, CA; $10 \mu \mathrm{g} / \mathrm{ml}) / \mathrm{M} 16$ medium at $37 \mathrm{C}$ for $2-3 \mathrm{~h}$. The embryos were incubated in $0.5 \%$ pronase (Sigma)/M2 medium solution for 5$20 \mathrm{~min}$ at room temperature (RT) until swelling of the zona pellucida occurred, and then they were transferred to $1 \%$ trisodium citrate (hypotonic treatment) for $20-40 \mathrm{~min}$ at RT. After fixation in $50 \%$ methanol and $10 \%$ acetic acid solution for 4 min at RT, these embryos were pushed out onto grease-free dry slides and vibrated immediately. The slides were then dried at $37 \mathrm{C}$, stained with 5\% Giemsa solution (Merck, Frankfurt, Germany), and examined with a light microscope.

\section{BrdU assay for cell division}

To analyze cell division in $4 n$ - and $2 n$-embryos, an immunofluorescence assay for the detection of BrdU incorporated into cellular DNA was performed with a BrdU Labeling and Detection Kit I (Roche, Indianapolis, IN). Namely, $4 n-$ and 2nembryos were cultured in BrdU labeling M16 medium (final BrdU concentration: $10 \mu \mathrm{M}$ ) for $1 \mathrm{~h}$ or $12 \mathrm{~h}$ at $37 \mathrm{C}$, and then they were washed 3 times with $0.1 \%$ polyvinylpyrolidone (PVP) (Sigma)/ phosphate buffered sodium (PBS). To remove the zona pellucida, the embryos were incubated with acidic Tyrode's solution. The embryos were fixed in methanol for $30 \mathrm{~min}$ and washed 6 times with $0.1 \%$ PVP/PBS. Then, the embryos were incubated in $2 \%$ Triton $X-100$ for $1 \mathrm{~h}$, washed 6 times with $0.1 \%$ PVP/PBS, and blocked for non-specific antigen-antibody reaction in $5 \%$ bovine serum albumin/PBS for $1 \mathrm{~h}$. These embryos were incubated in anti-BrdU mouse monoclonal antibody (diluted 1:10 with incubation buffer) overnight at RT, washed 3 times with blocking 
solution, and incubated in anti-mouse-Igfluorescein from sheep (diluted 1:10 with PBS) for 2 min at RT. Embryos were photographed under a fluorescence microscope, and embryos with BrdU positive nuclei were counted.

\section{Measurement of maximal projected areas}

Maximal projected areas of diploid (2n)-, 4n-, diploid/diploid (2n↔2n)-, and tetraploid/diploid $(4 n \leftrightarrow 2 n)$-blastocysts were measured with the NIH Image 1.62 software.

\section{Observation of EGFP-expressing cells in chimeric embryos}

The distribution and behavior of EGFPexpressing cells were compared between $2 \mathrm{n} \leftrightarrow 2 \mathrm{n}$ and $4 \mathrm{n} \leftrightarrow 2$ n-chimeric embryos from E3.75 to E4.5 with a fluorescence microscope.

\section{Statistical analysis}

Statistical differences between groups were analyzed by Student's $t$-test or the Tukey-Kramer method when appropriate.

\section{Results}

Behaviour of EGFP-expressing cells in chimeric embryos

EGFP-expressing $4 n-$ and $2 n$-cells were distributed in a mass in $4 n \leftrightarrow 2 n-$ and $2 n \leftrightarrow 2 n-$ chimeric morulae and blastocysts, respectively. These cells, in each chimeric blastocyst, were distributed in both the areas of the trophectoderm (TE) and the inner cell mass (ICM). The observation of EGFP-expressing cells revealed that the distribution of $4 n$-cells in $4 n \leftrightarrow 2 n$-chimeric embryos did not differ from that of $2 n$-cells in $2 n \leftrightarrow 2 n$-chimeric embryos (Fig. 1), and 4 n-cells were not eliminated from $4 \mathrm{n} \leftrightarrow 2 \mathrm{n}$-chimeric embryos from E3.75 to E4. 5 (Fig. 2).

\section{Development and cell division of $4 n$ embryos}

CB-treated embryos possessed about 80 chromosomes in cytogenetic analysis. Tetraploid embryos developed to the 4-cell-stage at $71.4 \mathrm{~h}$ post-hCG injection, and 2n-embryos developed to the 8-cell-stage at $69.6 \mathrm{~h}$. No significant difference
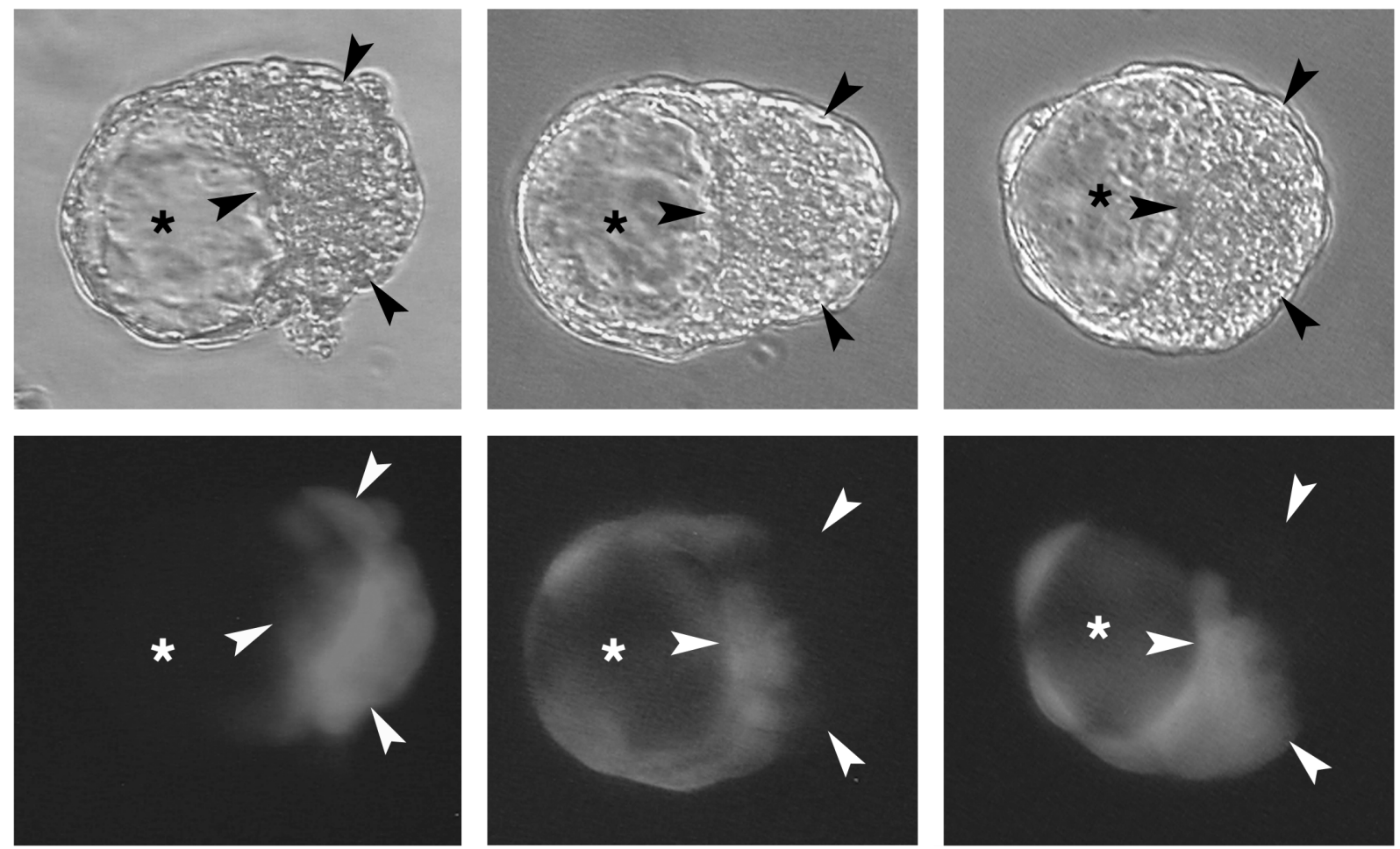

Fig. 1. Distribution of EGFP-expressing $4 n$ - and $2 n$-cells among $4 n \leftrightarrow 2 n$ - and $2 n \leftrightarrow 2 n$-chimeric embryos. Upper panels show blastocysts under a phase contrast microscope, and lower panels show the same field under a fluorescence microscope. EGFP-expressing $4 \mathrm{n}$ - and $2 \mathrm{n}$-cells in each chimeric blastocyst were distributed in every area. The asterisk indicates the cavity of the blastocyst, and arrowheads indicate the inner cell mass. 

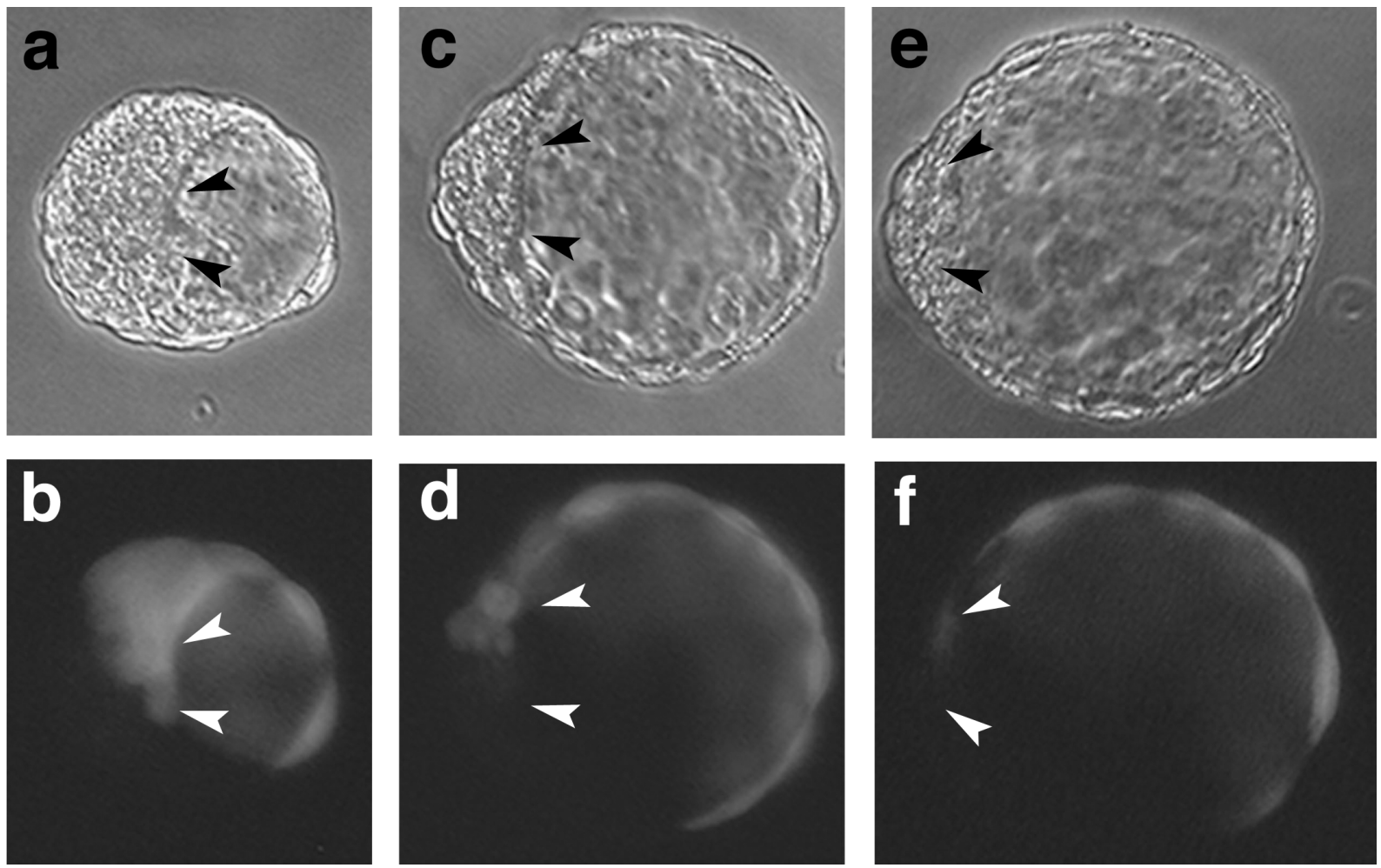

Fig. 2. Sequential distribution of EGFP-expressing $4 n$-cells in $4 n \leftrightarrow 2 n$-chimeric embryos. Upper panels show the identical blastocysts from E3.75 to E4.5 under a phase contrast microscope, and lower panels show the same field under a fluorescence microscope. Panels a) and b): E3.75; c) and d): E4.0; and e) and f): E4.5. Arrowheads indicate the inner cell mass.

in developmental rate was observed between $4 \mathrm{n}$ and 2 n-embryos. BrdU was incorporated in $87.5 \%$ of $4 \mathrm{n}$ - and $85.7 \%$ of $2 \mathrm{n}$-embryos after $1 \mathrm{~h}$ incubation in BrdU-labeling medium, and was incorporated in $100 \%$ of $4 \mathrm{n}$ - and $2 \mathrm{n}$-embryos after $12 \mathrm{~h}$ incubation (Fig. 3). BrdU was incorporated in all nuclei of BrdU-positive embryos. Blastocysts of $4 n, 2 n, 4 n /$ $2 \mathrm{n}$, and $2 \mathrm{n} / 2 \mathrm{n}$ had 22.6 cells, 47.9 cells, 83.9 cells, and 121.3 cells, respectively (Fig. 4). All of these values were significantly different (Tukey-Kramer: $\mathrm{p}<0.01)$.

\section{Morphological development}

There was no significant difference in morphological appearance between $4 n-$ and $2 n$ embryos, or between $4 n \leftrightarrow 2 n$ - and $2 n \leftrightarrow 2 n$-chimeric embryos during development. The $4 \mathrm{n}$ and $2 \mathrm{n}$ embryos began to compact from 2 to 8 cells and from 6 to 10 cells, respectively. But there was no significant difference among the groups in either the timing of the compaction or the formation of the blastocyst cavity (Table 1). The mean maximal

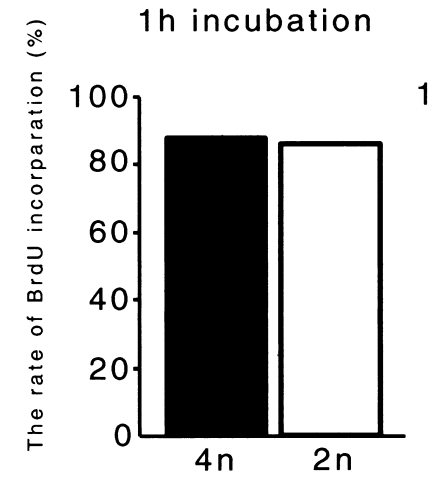

$12 \mathrm{~h}$ incubation

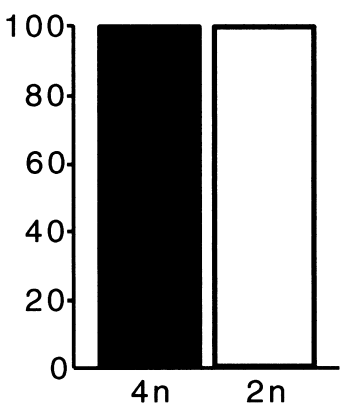

Fig. 3. Rate of incorporation of BrdU in $4 n$ and 2nembryos. BrdU was incorporated in all blastomeres after $1 \mathrm{~h}$ or $12 \mathrm{~h}$ incubation in BrdU labeling medium.

projected areas of the $4 n-, 2 n-, 4 n \leftrightarrow 2 n-$, and $2 \mathrm{n} \leftrightarrow 2 \mathrm{n}$-blastocysts were $8319.9 \mu \mathrm{m}^{2}, 8154.4 \mu \mathrm{m}^{2}$, $14063.7 \mu \mathrm{m}^{2}$, and $15997.9 \mu \mathrm{m}^{2}$, respectively. There was no significant difference in these values between $4 n$ - and 2 n-blastocysts, or between $4 \mathrm{n} \leftrightarrow 2 \mathrm{n}$ - and $2 \mathrm{n} \leftrightarrow 2 \mathrm{n}$-blastocysts. 


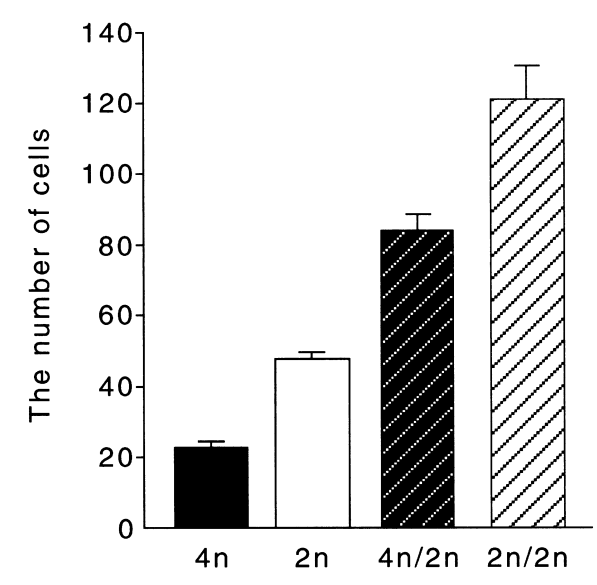

Fig. 4. Numbers of cells in $4 n-, 2 n-, 4 n \leftrightarrow 2 n-$ and $2 n \leftrightarrow 2 n-b l a s t o c y s t s$ with expanded cavities. Error bars indicate the SEM. The numbers of cells in blastocysts were as follows: $4 n(n=8), 2 n(n=9), 4 n / 2 n(n=8)$, and $2 n / 2 n(n=6)$. The numbers of cells were significantly different among groups (Tukey-Kramer: $\mathrm{p}<0.01$ for all comparisons).

Table 1. Timing of morphological development in $4 n-, 2 n-, 4 n \leftrightarrow 2 n-$, and $2 n \leftrightarrow 2 n$-embryos

\begin{tabular}{lcc}
\hline Embryo & Compaction & Blastocyst \\
\hline $4 \mathrm{n}$ & $83.9 \pm 1.3$ & $99.1 \pm 0.8$ \\
$2 \mathrm{n}$ & $82.4 \pm 2.0$ & $96.0 \pm 0.8$ \\
$4 \mathrm{n} / 2 \mathrm{n}$ & $\mathrm{NE}$ & $97.7 \pm 1.0$ \\
$2 \mathrm{n} / 2 \mathrm{n}$ & $\mathrm{NE}$ & $96.7 \pm 1.0$ \\
\hline
\end{tabular}

$\mathrm{NE}$, not examined. The values are the means \pm SEM of the post hCG time in hours. The numbers of compactioned embryos were as follows: $2 n(n=10)$ and $4 n(n=$ 10). The numbers of blastocysts were as follows: $2 n(n=$ $11), 4 n \quad(n=11), 4 n \leftrightarrow 2 n \quad(n=15)$, and $2 n \leftrightarrow 2 n \quad(n=15)$. There were no significant differences in the timing of compaction or blastocyst formation among the types of embryos.

\section{Discussion}

We succeeded in producing EGFP $\operatorname{Tg} 4 \mathrm{n} \leftrightarrow 2 \mathrm{n}$ chimeric embryos and in observing the distribution of EGFP-expressing 4 -cells in these embryos under a fluorescence microscope. Everett and West [12] and Everett et al. [13] reported that 4n-cells made a greater contribution to the TE than to the ICM of E3.5 chimeras; in the present experiments, however, we did not find a high population of $4 \mathrm{n}$ cells in the TE of E3.5 chimeras (data not shown), and chimeric embryos did not eliminate $4 \mathrm{n}$-cells until E4.5. The results of the BrdU incorporation assay revealed that the capabilities of cell division and DNA synthesis of $4 \mathrm{n}$ cells were almost the same as those of $2 \mathrm{n}$-cells until the 4-cell-compaction stage. In addition, the timing of compaction and blastulation seemed to be similar among the 2n-, $4 n-$, and chimeric embryos $(2 n \leftrightarrow 2 n$ and $4 n \leftrightarrow 2 n)$. Although the mechanisms of compaction and blastulation are still unclear, both $2 n$ - and $4 n$-cells in embryos have the capacity to synchronize with each other and complete the developmental events in the preimplantation period. This suggests that $4 n$-embryos and $4 n \leftrightarrow 2 n$-chimeric embryos might have the capacity to cleave and undergo morphogenesis in the early preimplantation period in the same way as $2 n$-embryos and $2 n \leftrightarrow 2 n$ chimeric embryos. However, the number of cells in 4 n-blastocysts with an expanded cavity (22.6) was slightly less than half of that in $2 n$ blastocysts (47.9) at the same stage. Also, the number of cells in $4 n \leftrightarrow 2 n$-chimeric blastocysts (83.9) was less than that predicted from $2 \mathrm{n} \leftrightarrow 2 \mathrm{n}$-chimeric blastocysts. These findings might suggest that cell death or prolongation of the cell cycle in 4 n-cells occurs at the blastocyst stage. In mouse embryos, cell cycle regulation begins to work after fertilization; however, judging from the fact that mouse embryos with a null mutation for the cyclin A2 gene can develop to the blastocyst stage [16, 17], there is a possibility that regulation of the embryonic cell cycle at the preimplantation period does not work as well as regulation of the somatic cell cycle. Therefore, $4 \mathrm{n}$-cells may be permitted to cleave at the preimplantation period. After the blastocyst stage, however, the cell cycle period may begin to be prolonged in $4 \mathrm{n}$-cells because the checkpoint control is completed. After implantation, 4 n-cells may be able to survive only in extra embryonic tissues permitted to proliferate slowly because of the prolongation of the cell cycle period. These characteristics of $4 \mathrm{n}$-cells may make some small contribution to the fetus during the postimplantation period.

In conclusion, analysis of chimeric embryos using EGFP Tg mice enabled us to examine the distribution of cells in chimeric embryos more clearly, noninvasively, sequentially, and easily than the ordinary method using immunostained sections. Moreover, this method of using EGFPexpressing cells provided the new insight that $4 n-$ 
cells contribute to the formation of both the TE and ICM. In addition, there is a possibility that cell death or prolongation of the cell cycle might affect the development of $4 n$ - and $4 n \leftrightarrow 2 n$-chimeric embryos. This method using EGFP Tg mouse embryos will be very useful for the future analysis of chimeric embryos.

\section{Acknowledgements}

We would like to thank Dr. Hideaki Tojo from the University of Tokyo for his generous donation of EGFP transgenic mice.

\section{References}

1. Kato M, Yamanouchi K, Ikawa M, Okabe M, Naito $\mathrm{K}$, Tojo $\mathrm{H}$. Efficient selection of transgenic mouse embryos using EGFP as a marker gene. Mol Reprod Dev 1999; 54: 43-48.

2. Snow MH. Tetraploid mouse embryos produced by cytochalasin B during cleavage. Nature 1973; 244: 513-515.

3. Eglitis MA. Formation of tetraploid mouse blastocysts following blastomere fusion with polyethylene glycol. J Exp Zool 1980; 213: 309-313.

4. Kaufman MH, Webb S. Postimplantation development of tetraploid mouse embryos produced by electrofusion. Development 1990; 110: 1121-1132.

5. O'Neill GT, Speirs S, Kaufman MH. Sexchromosome constitution of postimplantation tetraploid mouse embryos. Cytogenet Cell Genet 1990; 53: 191-195.

6. Snow MH. Embryonic development of tetraploid mice during the second half of gestation. J Embryol Exp Morphol 1975; 34: 707-721.

7. Kato $\mathbf{Y}$, Ohguro T, Tsunoda $\mathbf{Y}$. The viability of mouse tetraploid embryos produced by electorofusion at 2-cell stage. Anim Sci Technol 1992; 63: 157-161 (in Japanese).

8. James RM, Klerkx AH, Keighren M, Flockhart JH, West JD. Restricted distribution of tetraploid cells in mouse tetraploid/diploid chimaeras. Dev Biol 1995; $167: 213-226$.

9. Amano T, Kato $Y$, Tsunoda Y. Comparison of heattreated and tetraploid blastocysts for the production of completely ES-cell-derived mice. Zygote 2001; 9: 153-157.

10. Nagy A, Gocza E. Diaz EM, Prideaux VR, Ivanyi E,
Markkula M, Rossant J. Embryonic stem cells alone are able to support fetal development in the mouse. Development 1990; 110: 815-821.

11. Wang ZQ, Kiefer F, Urbanek, P, Wagner EF. Generation of completely embryonic stem cellderived mutant mice using tetraploid blastocyst injection. Mech Dev 1997; 62: 137-145.

12. Everett CA, West JD. The influence of ploidy on the distribution of cells in chimaeric mouse blastocysts. Zygote 1996; 4: 59-66.

13. Everett CA, Stark MH, West JD, Davidson D, Baldock RA. Three-dimensional reconstruction of tetraploid $\leftrightarrow$ diploid chimaeric mouse blastocysts. $J$ Anat 2000; 196: 341-346.

14. Everett CA, West JD. Evidence for selection against tetraploid cells in tetraploid $\Leftrightarrow$ diploid mouse chimaeras before the late blastocyst stage. Genet Res 1998; 72: 225-228.

15. Banzai M, Omoe K, Ishikawa H, Endo A. Viability, development and incidence of chromosome anomalies of preimplantation embryos from $\mathrm{XO}$ mice. Cytogenet Cell Genet 1995; 70: 273-277.

16. Murphy M, Stinnakre MG, Senamaud-Beaufort $C$, Winston N, Sweeney C, Kubeluka M, Carrington M, Brechot C, Sobczak-Thepot J. Delayed early embryonic lethality following disruption of the murine cyclin A2 gene. Nat Genet 1997; 15: 83-86.

17. Winston N, Bourgain-Guglielmetti F, Ciemerych MA, Kubiak JZ, Senamaud-Beaufort C, Carrington M, Brechot C, Sobczak-Thepot J. Early development of mouse embryos null mutant for the cyclin A2 gene occurs in the absence of maternallyderived cyclin A2 gene products. Dev Biol 2000; 223: 139-153. 